\title{
EL REFLEJO DEL DERECHO EN LA LITERATURA
}

François Ost

Université Saint-Louis. Bruselas

RESUMEN. En este artículo el autor presenta diversas formas en las que el Derecho puede reflejarse en la literatura. Algunas de ellas van desde la comparación interpretativa de textos jurídicos con textos literarios, hasta el estudio del lenguaje jurídico como la retórica judicial o parlamentaria. De todas las perspectivas, el autor se decanta explícitamente por una de ellas: aquella que asume las cuestiones más fundamentales del Derecho, la justicia y el poder. Esto es, el tipo de perspectiva que estudia el Derecho en la literatura. Para el autor, esta perspectiva que mira al Derecho en la literatura no debe tomarse como un mero divertimento académico, sino que debe ser entendida como una forma más de comprender los vericuetos de la razón práctica.

Palabras clave: Derecho y literatura, justicia, poder, razón práctica.

ABSTRACT. In this article, the author presents us with various ways in which law can be reflected in literature. Some of these range from the interpretative comparison between legal texts and literary texts to the study of legal language as judicial or parliamentary rhetoric. Among all these perspectives, the author explicitly opts for the one which deals with the most fundamental questions in law, that is to say justice and power. That is, the type of perspective from which law in literature is studied. In the author's opinion, this perspective, which considers law in literature, should not be seen as mere academic entertainment, but rather as one more way of understanding the twists and turns of practical reasoning.

Keywords: Law and Literature, justice, power, practical reasoning. 


\section{LA PLUMA Y LA ESPADA: UN PELIGROSO VÍNCULO}

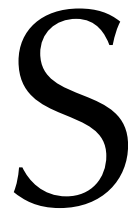

in duda hay quienes creen que el Derecho es dominio exclusivo de la profesión jurídica, que las exactas fórmulas que nacen de un sistema de "regulación normativa" sólo pueden ser conocimiento exclusivo de los abogados, y que, por lo tanto, la intrusión de cualquier lego en este campo denominado "positivo" del Derecho no es nada más... que literatura. Mucho me temo que a esta clase de personas no les interesará el diálogo que les propongo.

$\mathrm{Si}$, por otro lado, se cree, como muchos hacen, que el Derecho mantiene una relación esencial con la «imaginada institución social», como diría CASTORIADIS, que se pone en contacto con la «institución humana», en palabras de LEGENDRE, y que contribuye directamente a la constitución de un «orden simbólico compartido», usando una expresión de RiCOUER (en otras palabras, que su función primordial es la de expresar los valores colectivos de la sociedad y la de proveer de directrices a los individuos), entonces, se comprende que la fusión que hay entre el Derecho y la literatura no es casual.

Ahora bien, tomemos en cuenta que en los Estados Unidos existe un importante movimiento denominado "Law and Literature" que ha desarrollado todo un andamiaje de revistas especializadas, congresos universitarios y conferencias en torno al tema. En Francia y en Bélgica aún no se puede decir que esta perspectiva haya echado raíces, aunque podemos notar algunos destellos de interés. Resulta alentador que estos primeros pasos, aunque modestos, hayan surgido del interés común entre la profesión jurídica y la profesión literaria. Esto ha permitido fructuosos encuentros interdisciplinarios sin que se corra el riesgo de subestimar alguna de estas disciplinas o de reducirla a mera coartada auxiliar o a la mera explotación.

La relación entre Derecho y literatura podemos entenderla, al menos, desde tres distintas dimensiones:

Primero, nos encontramos con el derecho de la literatura, una perspectiva que normalmente ha sido reservada para los abogados. Bajo esta perspectiva se pueden analizar la libertad de expresión que gozan los autores, la historia jurídica de la censura, las demandas que surgieron a propósito de obras que, en su tiempo, fueron consideradas como escandalosas; desde Madame Bovary hasta Los versos satánicos, desde Las flores del mal hasta un Pierre MERTENS con su Une paix royale. Se pueden hacer comparaciones entre sistemas de marcas y de derechos de autor, se puede estudiar desde la regulación de bibliotecas públicas hasta los programas escolares o las políticas de subsidios editoriales.

Una segunda perspectiva puede ser el estudio del Derecho como literatura. En este caso, se puede considerar la retórica judicial y parlamentaria; se puede estudiar el estilo particular de los abogados, un estilo que es a la vez dogmático, tautológico y performativo. Se pueden comparar métodos de interpretación entre textos literarios y textos jurídicos. Esta clase de perspectiva ha sido desarrollada ampliamente en los Estados Unidos, basta echar un vistazo al trabajo de algunos autores como Ronald DwORKIN y Stanley FISH.

Por último, la perspectiva por la que yo me decanto estudia el Derecho en la literatura. Desde luego no se estudia el Derecho técnico, aquel que encontramos en los 
diarios oficiales, en los tratados y en las doctrinas (aunque cabe decir que en ciertas páginas de BALZAC se puede aprender mucho más acerca de la bancarrota que en antologías completas de jurisprudencia). No, el Derecho que busco en la literatura es el que asume las cuestiones más fundamentales a propósito de la justicia, del Derecho y del poder. Orestes y Hamlet nos invitaron a pasar por el estrecho sendero que separa la venganza de la justicia; es la conciencia problemática de Antígona la que cuestiona el reto del Derecho natural ante la institucionalización del Derecho en cada época; es la aparentemente arbitraria incriminación de Joseph K. la que levantó la esquina del velo que cubría la arcaica Ley de las necesidades, la que toma el mando cuando las instituciones están corrompidas y los procedimientos pervertidos ${ }^{1}$.

Así, gradualmente comienza a tomar forma un objeto común de estudio para las profesiones jurídica y literaria. Éste se articula en torno a las preguntas: 1) ¿Qué puede ofrecerle la literatura al Derecho?, y 2) ¿Qué gana la literatura con tener presente en sus obras al Derecho? ${ }^{2}$. Es cierto que existen ciertos riesgos en esta empresa, pero ¿no son necesariamente peligrosas las relaciones entre la pluma y la espada? El peligro se da cuando se confunden estos dos géneros; la literatura se torna moralizante o el Derecho deja de juzgar.

Por eso es importante que desde el principio distingamos claramente lo que separa al discurso jurídico del discurso literario. Mientras que el Derecho codifica la realidad, institucionalizándola en una estrecha red de requisitos previamente acordados, contemplados en un complejo sistema de límites y prohibiciones, la literatura, en cambio, libera las posibilidades del pensamiento, suspende nuestra certidumbre, despierta nuestra energía de su letargo, sacude identidades y convenciones y nos lleva a una encrucijada donde todo puede comenzar de cero.

Mientras que el Derecho selecciona, establece jerarquías y crea reglas, la narrativa literaria satisface un infinito de "variaciones imaginativas". Como un laboratorio de experimentos humanos, la literatura explora un amplio espectro de posiciones, valores y representaciones, sus pasajes no se retraen ante los límites más vertiginosos. Mientras tanto, el Derecho se enfrenta a situaciones ya estereotipadas a las que corresponden las leyes (decretos y reglamentos). La ficción literaria cultiva la ambigüedad de sus personajes y juega con la ambivalencia de las situaciones que ella misma crea. El Derecho sólo se desarrolla a partir de generalidades y abstracciones (sentencias que establecen precedentes y reglas que a fin de evitar la arbitrariedad que trae aparejada el privilegio —usando la terminología de ROUSSEAU - considera a los «ciudadanos como a un cuerpo»); la literatura, en cambio, se encuentra en constante movimiento, avanzando más y más sobre la singularidad de lo individual. Por lo tanto, por un lado tenemos la conformidad de situaciones promedio, mientras que, por el otro, el misterio del destino particular.

Todo esto, aunque resumido, es claramente cierto. No cabe duda de que el Derecho pertenece al sector de las formas institucionalizadas. Pero cómo ignorar que dentro de él operan incansables fuerzas centrífugas que algunas veces quedan deliberada-

${ }^{1}$ Véase mi trabajo, 2004: Raconter la loi. Aux sources de l'imaginaire juridique, Paris: Odile Jacob.

2 Véase Ost, François et al., 2001: Lettres et lois. Le droit au miroir de la littérature, Brussels: Publications des Facultés universitaires Saint-Louis. 
mente olvidadas por un compromiso con la racionalidad formal — por ejemplo, aquellas que hacen diariamente de los tribunales una escena de dramas individuales que para muchos no pueden reducirse a calificaciones predeterminadas, como si irremediablemente la vida siguiera hacia adelante, siempre hacia una renovada singularidad- Asimismo, no podemos negar que el Derecho sabe cómo usar el poder de las palabras (la retórica jurídica y parlamentaria, la hermenéutica doctrinal, el ingenio para fundamentar textos constitucionales) cuando las utiliza con múltiples recursos lingüísticos para crear un exceso de emoción y una ficticia inflación de los valores.

Frente a esto, no es coincidencia que Platón, visceral oponente de la democracia, se haya también opuesto arduamente a los dramas trágicos excluyéndolos de la educación de la juventud y, finalmente, haciéndolos desaparecer en su proyecto de una ciudad ideal. PlaTÓN entendió mejor que nadie el íntimo vínculo que hay entre ficción literaria (en su caso, la tragedia) y la auto-constitución de una ciudad (¿́acaso la ficción literaria no fue en siglos pasados cómplice del auto-cuestionamiento de una ciudad?), razón por la que se oponía a la disminución de la verdad y de la falsedad y a la confusión entre lo bueno y lo malo que se manejaban dentro de la tragedia. Después de estas sorprendentes declaraciones, los legisladores de la ciudad ideal de Magnesia, en su papel de Constituyentes, fueron quienes al final acabaron por escribir una tragedia, al rechazar a los autores de este género, quienes eran tanto dignos rivales como peligrosos alborotadores (pero esta tragedia a la que me refiero era de la "mayor excelencia”, purgaba las ambivalencias de la doxa y las incertidumbres de la praxis). Lo que podemos rescatar de esta historia es que la distinción entre ficción literaria y novela política es muy tenue y la competencia es furiosa. Ambas fueron pensadas, desde su particular punto de vista, como un intento de instituir un mundo a través de la confrontación de sus respectivos poderes, que en ocasiones se oponen y en otras se complementan.

Ahora bien, no cabe duda de que en la literatura se canalizan deudas de carácter individual; sin embargo, también sabemos que en la particularidad de cada libro hay ciertas instancias que alcanzan a tocar lo universal. Y si bien es cierto que algunas veces tanto el poeta como el novelista reinventan el lenguaje para librarse de los convencionalismos (frases trilladas y clichés), también es cierto que no pueden ignorar las reglas del juego de la comunicación, ni las leyes universales del significado. No hay duda de que la literatura se protege a sí misma de edificar discursos y, tampoco, de que se cuestiona constantemente acerca de nuestros códigos, estereotipos y sermones. También, todos sabemos que en ocasiones para la literatura éste es simplemente el camino más seguro para llegar a la radicalidad de los requisitos éticos y poder asumir la libertad y la responsabilidad que nos hace humanos. ¿Es que acaso no nos damos cuenta de que tanto nuestra identidad individual como nuestro bagaje colectivo sumergen sus raíces en los cimientos de la narración - tragedias familiares o políticas-, y que las características de ésta representan modelos habituales? La narración, como nos enseña Paul RICOEUR, se encuentra a mitad de camino entre la descripción y la prescripción, se muestra ante nosotros como un refugio de la razón práctica; la narración constantemente reorganiza la realidad con deseos de poderla dotar de significado, y la ubica al mismo nivel de los valores que son introducidos por su propia historia.

Éste es el objetivo al que dirijo mis primeros pasos: en lugar de mantener un diálogo de sordos entre un sistema jurídico codificado, institucionalizado, que mantiene 
un fuerte sentido de la efectividad y de la racionalidad, por un lado, y una literatura también institucionalizada, pero celosa de su ficción y de su irracionalidad, por el otro, más bien veo un ejercicio dialéctico entre ambas partes en el que las dos se reconocen como comunes, complejas y desarrolladas. Es decir, que entre el "todo vale" de la literatura y el "el tener que" del Derecho hay, al menos, tanta confrontación como interacción. Así es cómo la sociedad escoge su escenario, el cual está en medio de una gama de distintas variedades normativas que emergen de la creación literaria y que más tarde son impuestas por la autoridad de un sistema institucionalizado de obligaciones. Pero en cuanto estas elecciones son puestas sobre la mesa, son cuestionadas, subvertidas y matizadas - primero en el inmenso campo de la práctica, el que nunca se ajusta a la ley tanto como al legislador le hubiese gustado; después tras bambalinas del Derecho, donde se encuentra una especie de purgatorio normativo, una antesala de legalidad flexible; y, finalmente, en el parlamento, donde el Derecho mismo termina por rendirse ante los obstáculos que le impone una conciencia social que nunca descansa. Ex facto ius oritur (el Derecho deriva de los hechos) es la enseñanza de un clásico principio jurídico; sería más acertado decir ex fabula ius oritur (el Derecho deriva de la ficción) - y después de un prolongado momento de estabilidad normativa los elementos de estas elecciones regresan rápidamente a su lugar de origen.

¿Qué podemos, entonces, conseguir del estudio de esta confrontación entre Derecho y literatura? A un nivel muy superficial sólo es un erudito divertimento: las referencias literarias embellecen humanísticamente las frías expresiones jurídicas. Obviamente, este efecto carece de interés. No obstante, resulta mucho más esencial esperar que la literatura adopte un papel de crítica subversiva: Sócrates acusando a sus jueces, Antígona retando al orden de la ciudad, Alicia viajando a través de un espejo, y así, numerosos personajes literarios que le recuerdan al emperador que está desnudo o que está desafinado. Finalmente, en algunos casos, la literatura adopta una función de creación transformativa, sin necesidad de que ésta sea su principal intención. Esta versión literaria es fundacional, no sólo guiándonos para revisar nuestras ideas, sino también examinando los valores y, de vez en cuando, las prescripciones.

Por lo tanto, al explorar detrás del escenario de las instituciones jurídicas logramos revelar tanto sus ficciones como sus efectos trompe-l'oeil, tanto sus artificios como sus efectos teatrales. Esto produce, simultáneamente, un conocimiento crítico de las construcciones jurídicas y un incentivo para reformularlas con un conocimiento mucho más profundo del lenguaje. Asimismo, es un incentivo para conocer los vericuetos de la razón práctica.

\section{DE LA BIBLIA A KAFKA: EL DERECHO EXAMINADO POR LA LITERATURA}

Ahora me gustaría aventurarme por un camino sinuoso que nos llevará desde la Biblia hasta KAFKA, tomando por ruta a Esquilo y Defoe, tratando de descubrir el fascinante reflejo del Derecho en la literatura y algo sobre sus respectivos poderes.

Los primeros ejemplos los podemos encontrar en algunas de las versiones sobre la voluntad creadora del Derecho. Aquí me limitare únicamente a contemplar dos de ellos: la explicación bíblica de los sucesos del Monte Sinaí y el Protágoras de PLATÓN. 
Ambas versiones son hipotéticamente edificantes; por si fuera poco, son los cimientos de los grandes relatos políticos donde se habla del origen del Derecho y de las instituciones. Por ser así, esperaríamos una especie de epifanía por parte del legisladorsoberano, algo como una fuente trascendental de legalidad y legitimidad. No obstante, es cierto que estas dos versiones no carecen de una dimensión trascendental, pero tampoco las podemos reducir sólo a ello. En absoluto se trata de una imposición unilateral del Derecho, por el contrario, a través de ellas somos testigos de una nueva invención procedimental para crearlo. De un diálogo que se erige en contra de alianzas hechas tras el telón. En el Génesis y en la parte Deuterocanónica la principal alianza es con Yahvé; en el contexto ateniense se trata de la autodeterminación constitutiva de la ciudad. En lugar de recibir una legislación de contenido codificado y definitivo, en ambas versiones podemos apreciar la negociación y la formulación de principios que quedan abiertos a una infinidad de interpretaciones. De esta manera, el acento no recae exclusivamente en el Derecho, sino más bien en sus condiciones de aceptabilidad: libertad y responsabilidad para los judíos, justicia y respeto en la polis griega.

Ambas versiones juegan, pues, un papel que está ligado intrínsecamente con la clara idea de institucionalizar y fundamentar una crítica subversiva en contra de los poderes establecidos — en sus porcentajes de explotación y desigualdad—. Los judíos tuvieron que soportar la esclavitud en Egipto antes de recibir las leyes del Monte Sinaí. Cruzar el Mar Rojo y, con todos sus riesgos, el desierto para poderse liberar del cautiverio y encontrar la libertad. Asimismo, tuvieron que recordar una vieja promesa que hablaba sobre la libertad y el pacto. En este sentido, no es coincidencia que la primera institución creada por Moisés en el desierto haya sido el Sabbath: un día a la semana que los libera de todas las obligaciones creadas por el día a día, constituyéndose en una fórmula para liberarse de ese "Egipto interno" que siempre los amenaza y que al final les sirve para asumir su nueva libertad. En suma, no es cuestión de experimentar una libertad plena a priori difícil de alcanzar (como ha sido vanamente soñada por los modernos pensadores del contrato social), sino es cuestión de atravesar un largo camino, lleno de retos y vicisitudes, que es el que lleva a la liberación. Más tarde, la historia del Becerro de Oro mostraría qué tan frágil es en realidad esta liberación.

Por este motivo, el episodio donde se dictan las leyes lo encontramos inmediatamente después. La memoria colectiva y la imaginativa popular relatan que Yahvé, el Todopoderoso, ante un pueblo tembloroso que se ubicaba al pie de la montaña y en medio de una tormenta de truenos y relámpagos, grabó los "Diez Mandamientos" en las "Tablas de la Ley". Una lectura más cuidadosa de este pasaje presenta las cosas de muy diferente manera. Primero, podemos decir que más bien se trata de las "palabras de Dios" que de "Mandatos" y, segundo, que se trata de las "Tablas de un pacto" más que de las "Tablas de la Ley" — diferencias no poco significativas.

Veamos el papel que Moisés desempeñó en estos asuntos. Moisés reclama que, lejos de ser una especie de notario o de transcriptor de las palabras divinas, es un activo negociador entre Dios y el pueblo. Moisés, después de escalar varias veces la montaña, de sufrir numerosos intentos fracasados por comunicar la Ley, y a pesar del drama de haber roto las tablas y de amenazar a Yahvé con retirarse si no mantenía su promesa de aceptar a los hombres tal y como son, desagradecidos y pecadores, siempre logra "mantener contacto". En su último encuentro dentro de la "tienda de reuniones", en un espacio intermedio entre la llanura y la montaña, finalmente se sellan los términos 
del convenio con un texto pactado entre ambas partes. El resultado es un Derecho vivo que requiere de constante estudio, guardado en el Arca de los convenios y abierto a la interpretación de generaciones sucesoras. Debido a este pacto, el mismo Dios tiene la obligación de obedecer la Ley, como Moisés no deja de recordárselo cuando Yahvé, lleno de ira e indignación, amenaza con aplicar justicia sumaria.

Este pasaje es ampliamente significativo, pues muestra que lo esencial no es el Derecho (no matarás, no robarás), sino las condiciones de aceptación y de aplicación que el pueblo señala. En este caso, el pueblo, tras un largo transcurso que los liberó de la esclavitud, se enfrentó a una progresiva inflexión de libertad responsable. El hombre descubre que la libertad es buscada por todos y que es correlativa de deberes, por lo que resulta una ilusión, e incluso inhumano, entenderla de manera autárquica o solipsista.

Esta misma línea argumentativa la podemos encontrar en el Protágoras de PLATÓN, escrito en el año 432 a. C. Platón nos cuenta que Zeus se encuentra ansioso por la supervivencia de la raza humana al ver que ésta se ha dividido por guerras interminables. Prometeo les ha regalado a los hombres los secretos del fuego y la tecnología, pero si no cuentan con vínculos civiles y el arte de la política, se seguirán viendo amenazados por disputas mortales. De tal manera, Zeus envía a un mensajero, Hermes, quien trae al mundo un nuevo regalo, «el que servirá para restablecer el orden en las ciudades». En este caso, esperaríamos que la autoridad divina les presentase a los hombres un código, una constitución o una ley, de una u otra forma un corpus de reglas, la "perfecta" ilustración de la ley divina que deberá establecer con certidumbre los límites de lo prohibido y lo permitido. Pero no es así, nos equivocamos, el secreto del "vínculo civil" pretende ser un regalo aún más preciado: aidos y diké, respeto y justicia. Justicia en el compartir y respeto a la esencia que encontramos en todos los hombres. Siendo la única posibilidad para el Derecho el tomarlos como sus cimientos trascendentales y como una condición necesaria para tender hacia una civilidad que fomente su aceptación. Aunque con una consideración adicional que vale su peso en sabiduría: Hermes le pregunta a Zeus si es que aidos y diké serán distribuidos sólo entre algunos especialistas de la misma forma como se hizo con el talento artístico y tecnológico, a lo que Zeus responde magníficamente que «Han de ser repartidos entre todos los hombres, dado que las ciudades no podrán existir sin que todos formen parte de ellas». Por lo tanto, las cuestiones del Derecho y la justicia son privilegio público y no sólo de algunos especialistas. Asimismo, forman parte de un constante aprendizaje y de una deliberación que no tiene ni términos ni modelos preestablecidos, representan los reclamos de una paideia democrática, el objetivo de una "procedimentalización", como diríamos hoy en día siguiendo a HABERMAS. Pero esta deliberación no es únicamente formal, sino llena de contenido, pues se encuentra orientada nada menos que por aidos y diké: justicia y respeto a la humanidad por parte de los seres humanos.

Se pueden extraer aún muchos otros puntos de estos textos; sin embargo, aquí me limitaré a uno que considero esencial: si el Derecho no se basa en el ejercicio de una libertad responsable, entonces, sólo es una brutal opresión o una necesidad banal.

La venganza es otra cuestión que nos ofrece un amplio espectro para investigar las relaciones entre Derecho y literatura. Específicamente, la venganza se trata del paso que hay entre la revancha y una justicia pública, es decir, con la presencia de un tercero imparcial y con la mediación del Derecho. La pieza clave de mi análisis será la 
Oresteia de ESQUILO, ya que es la única trilogía sobre este tema de la que tenemos conocimiento.

ESQUILO describe en tres obras, por un lado, las aporías de la tradicional lex talionis —ojo por ojo-, donde el derramamiento de sangre es el llamado a la venganza de generación en generación (primero de Ifigenia luego de Agamenón y, finalmente, de Clitemnestra) y, por el otro, la institución ateniense de un tribunal humano, el que finalmente termina acusando a Orestes de matricidio, mostrándonos un ciclo virtualmente infinito de represalias.

Dado que este texto fue escrito en la época en que se fundaron las instituciones judiciales en Atenas durante el siglo $\mathrm{V}$ a. C., puede resultar tentador ver en él una apología de la justicia institucionalizada, en contraste con un sistema de revanchas. Sin embargo, el texto rechaza una lectura unilateral. Bajo la interpretación de René GIRARD, no es más que un camino de actos incontrolables y desproporcionados que sólo llevan a una violencia interminable. A diferencia de esta reducida interpretación, el Oresteia nos revela que no importa qué tan violenta sea la venganza, ya que ésta puede ser tasada e institucionalizada.

En primera instancia, la venganza es tomada como el resultado de la voluntad divina; así, en la historia aparecen las aterradoras Erinias que tratan de vengar los modestos esfuerzos de justicia de Zeus. En este punto, la justicia divina y la justicia humana se identifican. Los términos "justicia" y "venganza" se utilizan indistintamente; diké es aplicada tanto para las reprimendas, como para la venganza y la justicia en general. De tal manera, podemos notar que mientras la venganza institucionalizada y ritualizada se encuentra inscrita en los códigos de honor de ciertos grupos (en este caso, en la clase noble de guerreros), al mismo tiempo, participa en un sistema de intercambios recíprocos que se rigen por las reglas básicas del dar y recibir, una especie de trueque que dado a los prejuicios se debe honorar so pena de perder la dignidad.

Con la aparición de las ciudades-estado y con el experimento democrático de Atenas, este sistema pronto deja de ser sostenible. Las leyes ya no se pueden entender como costumbres y códigos de honor cuasi-familiares que fueron heredados por un régimen cerrado de castas. Por el contrario, ahora se deben ver a mayor escala, bajo el entendido de que el demos entero está compuesto por la mezcla de distintas clases sociales y que los privilegios de ciertas castas ya no existen. Ahora, las supuestamente imparciales instituciones judiciales son las encargadas de hablar en nombre del bien común. Precisamente, ésta es la historia que se cuenta en Las Euménides a propósito de la institución del Areópago de Atenea.

No obstante, no fue fácil deshacerse completamente del viejo sistema. Claramente, el voto del Areópago fue lo que detuvo a las Erinias de ser quienes aplicasen justicia a Orestes. La mayoría de los jueces humanos ya habían votado a favor de su culpabilidad, como una legítima encarnación de la lex talionis, por lo tanto, es únicamente gracias al voto de Atenea como se logra la absolución de Orestes. Atenea al crear el Areópago fue muy cuidadosa en considerar, palabra por palabra, el discurso "político" de las Erinias, que como una muralla en contra de la violencia insistían en que los cimientos de la ciudad son el respeto a la ley y el miedo al castigo: «Ni anarquía ni despotismo». 
Por lo tanto, la absolución de Orestes no es el fin de la historia. Atenea consigue disuadir a las Erinias a través de una «gentil persuasión» de descargar su furia sobre Atenas. Ante esto, ellas acceden a cambiar su papel de temerosos verdugos por el de protectoras de la ciudad (Euménides), siempre y cuando se les garantizara que se levantaría en el corazón de la ciudad un altar que los atenienses habrían de venerar. Vemos así con claridad cómo la voluntad de Atenea se entrega al corazón del Derecho moderno cuando funda estos tabúes que están representados por los demonios. Su mensaje, lejos de haberlo olvidado o reprimido, lo hemos integrado y subsumido en una perspectiva mucho más amplia, la que en determinadas circunstancias sabe ceder ante la igualdad del hombre y el perdón. El Derecho penal moderno está casi exclusivamente dedicado a la reparación del daño y a la disuasión. Sin embargo, no ha desaparecido del todo la idea del castigo como medio de retribución. El Derecho ha logrado con éxito imponer sus ficciones mediante el poder de sus acciones. El mundo artificial que ha creado ha resistido el peso del mundo real y triunfado sobre él. Tal y como afirma James BOYD WHITE, al sospechoso se le presume inocente, al culpable se le absuelve y al condenado se le otorga amnistía ${ }^{3}$.

No veamos en este "final feliz" dejos de reproche o de ira. Jean-Pierre VERnANT ha mostrado convincentemente que la tragedia no se puede reducir, por ningún motivo, a un medio propagandístico de la ideología democrática ${ }^{4}$. Muy por el contrario, es la conciencia crítica que nos acompaña en la nueva y riesgosa experiencia de ver que el poder es ejercitado por el demos. Podemos lograrnos convencer de ello si hacemos hincapié en que únicamente fue el voto de Atenea el que logró inclinar la balanza a favor de una decisión mucho más "moderna"; también si notamos que al institucionalizar las alabanzas de las Erinias-Euménides en el corazón de la ciudad, se les impuso a los ciudadanos un ejemplo de cómo en una sociedad siempre es posible regresar a la violencia que precede a dicha institución. Es una forma de vacunar al grupo social con el antivirus de esta patología, de tal suerte que cree defensas en contra de ella.

Años más tarde, cuando Eurípides escribe sobre el juicio de Orestes, el tono cambia radicalmente. En esta ocasión, el demos está corrompido y es guiado erróneamente por oradores sin escrúpulos. El Derecho de la ciudad se pervierte frente al poder de los intereses privados. De este modo, Orestes y Electra son condenados y sólo logran escapar tras la intervención de Apolo, por una auténtica deus ex machina, que los apresura hacia Atenas donde serán juzgados por un Tribunal divino. No hay duda en que se quiere conservar la leyenda, sin embargo, el mito sólo es preservado en cuanto a su forma haciendo desaparecer todo su espíritu ya que en esta ocasión el Derecho es incapaz de limitar el poder y los intereses privados. La violencia vuelve a reinar y los juicios divinos y humanos vuelven a aparecer completamente desasociados.

La ficción literaria, en vez de mostrarnos los contornos de una institución, nos informa sobre todas las posibles deformaciones que ésta puede llegar a sufrir. Esta misma línea argumentativa encuentra uno de sus ejemplos más famosos en la tragedia de Antígona escrita por SófOCLES. Con esta obra, sin duda, estaríamos dispuestos a

\footnotetext{
3 Véase Boyd White, James, 1985: The legal imagination, Chicago: University of Chicago Press. También véase del mismo autor, 2000: From Expectation to Experience, Ann Arbor: University of Michigan Press.

${ }^{4}$ Véase VernANT, Jean-Pierre, 1972: «Le moment historique de la tragédie en Grèce», en Mythe et Tragédie en Grèce ancienne, Vernant, J.-P., y Vidal-Naquet, P., Paris: Maspero, p. 15.
} 
creer que la tragedia griega opera como una paideia (aprendizaje) política que celebra que en la ciudad nazcan "nuevas" instituciones y procedimientos que ayudarán a dejar atrás las viejas leyes de la aristocracia griega. Pero, en realidad, en este trabajo no encontramos rasgos de propaganda ateniense y, mucho menos, de halagos a favor del nuevo régimen. Por el contrario, frente al nuevo poder encarnado por Creonte es fácil simpatizar con la conciencia problemática de Antígona. Es ella quien le recuerda a Creonte que el Rey no tiene permiso de hacer lo que le venga en gana, que el dominio familiar y el destino de los muertos quedan fuera de su competencia. Con esta situación se pretende que el nomos político ceda ante la nomina que tiene origen divino (vieja ley de tiempos inmemoriales). Sin embargo, como el coro le recuerda a Antígona, ella «únicamente busca consejo en sí misma» encerrándose en una soledad que le priva del acceso a una discusión pública. Dedicada exclusivamente al amor por ella misma y por los de su misma sangre (philoi), restringe posibilidad a la alteridad de eros y morirá sola y sin éxito. Ciertamente, esta actitud hace que su postura no sea completamente convincente. Se puede pensar que Antígona y Creonte representan cada uno una mitad del mundo, pero únicamente una: lo privado $v s$. lo público, los muertos vs. los vivos, el derecho natural vs. el derecho institucionalizado, la ética de la convicción vs. la ética de la responsabilidad.

Ahora bien, no hay duda de si están equitativamente distribuidos el bien y el mal en esta batalla del nomoi, de si la legitimidad no está enteramente situada en un solo lado, o de si no es fácil decidir a priori si debemos o no obedecer las órdenes de Creonte, porque SófOCLES en este trabajo se mueve alrededor de la cuestión de lo justo. Esto es porque posiblemente en una ciudad buena dichas cuestiones están menos relacionadas con el contenido de la ley que con el problema de definir lo justo en general, o de revisar, si es necesario, lo que entendemos por justo en cada caso particular. Como diríamos hoy en día, si una decisión en abstracto se considera en principio justa, pero después, en un caso particular, o con el paso del tiempo, se le considera injusta es porque su aplicación requiere ser "procedimentalizada", es decir, hay que regresarla a la pizarra, revisarla y examinarla.

De aquí se sigue que en una ciudad justa la verdadera naturaleza del Derecho es que esté abierto a la discusión, a la revisión y a la ponderación. Asimismo, como vanidosamente Hemon quiso hacerle entender a su padre, la verdadera falta política de la democracia es el rechazo del diálogo, el empecinamiento de insistir en una decisión que ha sido, una y otra vez, rechazada. De esta manera, me parece que quizá es Hemon quien mejor ha representado la perspectiva de SÓFOCLES cuando afirma que «en realidad no se trata de que una persona tenga el dominio privado», sino «que no hay ciudad que pertenezca a una sola persona».

Con el renacimiento y la edad moderna el centro de gravedad del Derecho giró hacia el individuo y hacia sus derechos "subjetivos", siendo la propiedad privada el caso arquetípico. Este modelo triunfaría en el concepto de Derecho liberal de corte angloamericano, donde la función de la colectividad es la de proteger los derechos que los individuos han heredado directamente de su naturaleza. A partir de entonces, la soberanía ya no recae en el Estado sino en el individuo; LEGENDRE habla de las instituciones individuales como una multitud de «mini-Estados».

Bajo este tenor, Robinson Crusoe, escrito por Daniel Defoe en 1719, es un libro fundacional en esta revolución de la autodeterminación y la autosuficiencia del hombre. 
ROUSSEAU consideraba este libro como esencial (tanto que, por algún tiempo, lo hizo lectura obligatoria de su Emilio), que al lado de Fausto y de Don Juan era uno de los raros modernos mitos de Occidente. A la guisa de una aventura tropical escrita en el crudo estilo de la bitácora de un marino inglés, esta historia nos cuenta cómo un hombre reconstruye progresivamente su identidad al reapropiarse de su ambiente (la isla es cultivada, los animales domesticados), con dominio de su situación construye una sociedad embrionaria basada únicamente en principios individualistas. Esta experiencia al borde de la supervivencia hace un recuento de cómo la soberanía individual - con radical solipsismo - se reapropia del mundo. De esta manera se presenta ante el mundo, como acto de la providencia, un modelo de libertad y de propiedad universal, una especie de re-cimentación del mundo basada en el individuo; visto como propietario y libre empresario.

Así, el viejo lema de los reyes ingleses: "Dieu et mon droit", recibe un nuevo significado y se universaliza. A partir de ahora, confiando plenamente en la providencia ("In God we Trust"), cada individuo será el rey de sus dominios, dominios que a priori no tienen límites.

No obstante, Robinson Crusoe no es una simple historia de aventuras. Manteniendo la definición de LÉVI-STRAUSS se eleva a nivel de mito al aparecer como «una explicación de los orígenes (¿qué puede ser más originario que una isla?) que provee de una respuesta narrativa a una de las contradicciones ideológicas que recorren la sociedad desde sus inicios». A esta contradicción ideológica de la Inglaterra de Cromwell la llamaré «el dilema del puritano»; el quid de esta cuestión es cómo ser rico y virtuoso al mismo tiempo. De tal manera, el puritano Robinson prueba, suficientemente, su virtud con el ascético trabajo que lleva a cabo durante 28 años en la isla y, una vez que regresa al continente, se vuelve millonario gracias a sus plantíos cultivados en Brasil antes del naufragio. Así, logra algo que para los protestantes luteranos parecía tan difícil de conseguir. De este modo, la historia se puede catalogar como un éxito brillante tanto para el emblema del triunfo individual (aquel del hombre autodeterminado que sirve de modelo para innumerables generaciones de adolescentes) como para confirmar la doctrina de la predestinación del hombre, la que ve como signo irrefutable de elección divina el éxito en los negocios. A partir de aquí, en vez de existir una contradicción entre virtud y prosperidad, podemos decir que ambos están implicados. De la misma forma lo ha mostrado Max WeBER en su The Protestant Ethics and the Spirit of Capitalism.

Aun así, es difícil eludir la sensación de que esta "exitosa obra" abriga un cierto número de ficciones. Los elementos para deconstruir el mito los encontramos dentro de sí mismo. En primer lugar, hay una ficción desde el inicio: Robinson, lejos de construir en una isla desierta y virgen una pequeña Inglaterra, tabula rasa, en realidad, rescata del naufragio todo aquello que lo conecta con la civilización. Asimismo, contribuyen en algo los 30 años previos de su educación continental. Otra ficción la encontramos en el dominio: en términos jurídicos (a partir de la subjetividad jurídica relacionada con el dominio y la propiedad) el poder que Robinson ejerce sobre la isla y sobre los "sujetos" que en ella se encuentran es reducido y parcial, también falla en darse cuenta de la ferocidad de la isla, así como de la alteridad de Viernes y de los misterios de su propio cuerpo. Por último, nos encontramos con la ficción de la supuesta "solución" del dilema del puritano, si Robinson, en realidad, prueba que es posible 
ser rico y virtuoso al mismo tiempo, le cuesta una obvia y completamente falsa separación de ambas esferas: el imaginado escenario donde el ermitaño logra su salvación a través del trabajo y el escenario real del comercio internacional donde las ganancias de sus plantíos se fueron acumulando gracias, fundamentalmente, al trabajo de los esclavos negros que él mismo habría llevado.

Hay que tener en cuenta, al mismo tiempo, que la legitimación de la propiedad privada de John LOCKE, quien era un puritano inglés contemporáneo de DEFOE, revela una hazaña comparable a la de una prestidigitación ideológica: la propiedad privada, mientras no se desperdicie y pueda ser medida por el producto del trabajo personal, está justificada por el Derecho natural. A esta demostración subyace una concepción (que ha sido aceptada con entusiasmo) sobre el mercado y la economía monetaria, que ignora todas estas reservas y que autoriza la acumulación ilimitada del capital, así como la explotación del trabajo de otros.

Pero en la naturaleza del mito está la capacidad de sugerir varias versiones. Si en los siglos XVIII y XIX Robinson Crusoe estaba en su apogeo (en muchos aspectos Robinson era considerado el arquetipo del éxito occidental), durante el siglo XX no; por el contrario, este siglo se considera como el destructor de mitos. Es de esperar que a partir de entonces los dos valores más representativos de este mito acaben por disolverse: la ilimitada confianza en la Providencia y la inocencia de creer haber conquistado la apropiación. Así pues, nos encontramos con versiones de un Robinson desilusionado (SaintJohn Perse), desempleado y flojo (Valéry), frívolo (Giraudoux), salvaje y adusto (Coetzee), deshumanizado (Tournier), violento y regresivo (Golding).

La imagen del ermitaño exitoso que había sido reflejada durante el siglo pasado se hace borrosa comenzando a refutarse su buena voluntad. Al punto de que deja de ser legítima la apropiación del mundo por parte del Derecho. Las sociedades occidentales se sumergen en un remordimiento antropológico que las lleva a redescubrir la armonía natural y a formular distintas versiones sobre el origen social. Un notable ejemplo de esta versión del origen social basada en el crimen y en el miedo es El señor de las moscas de William Golding. En esta ocasión podemos apreciar de nuevo cómo en la literatura un mito fundacional, como en el caso Robinson Crusoe (la base del moderno individualismo posesivo de las sociedades occidentales), no está demasiado lejos de la más radical deconstrucción.

Giremos ahora nuestras reflexiones y regresemos a la violencia originaria del Monte Sinaí y de las tragedias griegas donde ésta se entendía como el medio para lograr su libertad. Pero ahora volteando a ver al autor más emblemático del siglo xx. Franz Kafka era un judío checo que escribía en alemán durante la década de los veinte, abogado practicante obsesionado con la Ley (o el Derecho; no sé cuál de estas dos perspectivas sea la más apropiada).

Su enigmático trabajo, que conocemos por sus escritos públicos (los que él hubiese querido destruir) y sus escritos privados o semi-privados (como Carta a su padre), denuncia el espectáculo de pervertir la justicia y muestra, experimentalmente, una imagen socavada de las instituciones judiciales. Todos recordamos a sus distraídos o perversos legisladores, sus jueces arbitrarios, sus abogados idiotas o sus verdugos quisquillosos. Pero ¿qué hay detrás de esta monstruosa representación del ámbito jurídico? 
Tenemos la sensación de que Kafka no se sitúa en la tradicional línea crítica de la justicia que va de Aristófanes a Dickens, de La Fontaine a Anatole France, sino que con sus escritos él crea otros abismos más profundos. Para Kafka, las "disfuncionalidades" de la justicia no son más que meros síntomas. Pero ¿síntomas de qué exactamente? Algunos de sus críticos, tales como Max Blod ${ }^{5}$ o Alexandre Viallatte ${ }^{6}$, ven en Kafka una especie de santo incitado por un ideal de justicia que es inaccesible, el que sólo se puede obtener mediante la intervención de un tribunal divino (así, el 20 de diciembre de 1910 en su Diario escribía: «iInvisible tribunal, si tan sólo tú pudieses venir!»). Otros sostienen una explicación biográfica, como Elias CANETTI $^{7}$, quien interpreta Elproceso como una traducción literal de las acusaciones dirigidas a KAFKA cuando su boda fue dramáticamente cancelada. Deleuze y Guattari rechazan que la explicación se deba a cargos de conciencia, y leen su trabajo como el de un impertinente, de espíritu perverso, que busca escapar de las restricciones de la Ley, especialmente de la autoridad paterna, a través de sus vastos y reconstructivos trabajos ${ }^{8}$.

Numerosos críticos, entre ellos Hannah ARENDT, han visto en Kafka una profética anticipación del mundo totalitarista (negro y rojo) que se desataría en el centro de Europa, especialmente, dentro de las comunidades judías a las que Kafka pertenecía ${ }^{9}$.

Cada una de estas interpretaciones tienen algún grado de verdad, sin embargo, ninguna de ellas agota el completo significado de este enigmático trabajo. Me gustaría proponer una lectura de Kafka en términos del fracaso de la simbólica estructuración de la intersubjetividad y su correlativa regresión a la arcaica Ley de la necesidad. Explorarlo de esta manera nos lleva al diálogo que hay entre el Derecho y la literatura.

En este sentido, tomemos en consideración las enseñanzas de Paul RicOEUR, quien nos recuerda que acceder al universo de las leyes (morales y jurídicas) presupone internalizar una relación simbólica que está representada por el uso de los pronombres personales: donde el "yo" se traduce en la presunción de la autonomía del sujeto que habla en primera persona, el "tú" se traduce en el reconocimiento de otros y el "él" que representa una tercera persona. Así, podemos afirmar que la obra de Kafka, especialmente El proceso, se traduce en el colapso de esta constitución simbólica de la sociedad y, especialmente, en la imposibilidad de que un tercero (el Derecho, el juez) pueda intervenir como mediador, al triangular las otras dos partes e inscribir su relación inter-individual en una universalidad mucho más amplia.

Una primera etapa de este proceso es el colapso del pronombre "él"; esta etapa es el tema kafkiano por excelencia, la inaccesibilidad de los jueces y la ininteligibilidad del Derecho. Cada vez que crees haberlos encontrado, desaparecen. Y lo único que queda del Derecho es el eco de viejas leyendas y supersticiones. En el juicio de Joseph K., a pesar de todos sus esfuerzos él nunca llega a conocer a sus jueces. Y como

${ }^{5}$ Véase Blod, Max, 1991: Franz Kafka. Souvenirs et documents, trad. ZyLberberG, H., Paris: Gallimard, Folio, p. 75.

6 Véase Vialatte, Alexadre, 2001: Mon Kafka, Paris: Les Belles Lettres (Folio), p. 81.

7 Véase CANETTI, Elias, 1972: L'autre procès. Lettres de Kafka à Félice, Paris: Gallimard.

${ }^{8}$ Véase Deleuze, Gilles, y GuatTari, Félix, 1986: Kafka: Toward a Minor Literature, trad. Polan, Dana, Minneapolis: University of Minnesota Press.

9 Véase ARENDT, Hannah, 2001: «Franz Kafka», en La tradition cachée, Paris: Christian Bourgeois, 10/18, p. 81 . 
"hombre de campo" hubiese esperado toda su vida para obtener el permiso de cruzar las puertas de la Ley.

La segunda etapa en la deconstrucción de este universo simbólico está marcada por la degeneración del "tú"; por la corrupción de la figura de la autoridad. Desde el modelo de su propio padre, a quien en las Cartas a su padre Kafka describe como un tirano doméstico, hasta las figuras de autoridad representadas en su trabajo que nunca logran transmitir la Ley. De ahí la proliferación de oficiales arbitrarios y crueles (In the Penal Colony), de servidores públicos abusivos y quisquillosos (The Castle), de jueces corruptos (Le substitut), de legisladores déspotas (La Requête, Au sujet des lois). Un universo donde al lado de inmerecidos privilegios existen castigos injustos que hacen de la justicia una alegoría que evoca la imagen de la Diana cazadora (El proceso). Es una justicia perversa y corrupta, incapaz de asumir la Ley, que extrañamente se encuentra muy cercana a sus víctimas: los acusados.

Por último, la tercera etapa, el derrumbe del "yo", representa el colapso de la institución que simboliza la sociabilidad. Tras una devoradora culpabilidad y ante la ausencia de la Ley y el fracaso de los jueces por expresarla [«el tribunal no requiere nada de ti. Te toma cuando llegas y te desecha cuando te vas» (El proceso)], parece como si el "yo/ser" tuviese que auto-sustituirse. De esta manera Gnawed se desgarra entre protestas y reclamos de inocencia («diabólica en toda su inocencia»), Joseph K. (que es el símbolo del héroe kafkiano y una represtación explícita de él mismo) vive una lenta metamorfosis (otro tema kafkiano por excelencia) que va de la inocencia a la culpabilidad. Siendo este cambio el objeto principal que prolifera en toda su obra; el cuerpo representado por K. sufre transformaciones de toda clase, a veces en animales y, raras veces, en cosas, y presenta los juicios de los tribunales en procesos cuasinaturales.

Esta última característica es esencial y nos conduce a una eventual regresión. El colapso del sistema de símbolos que constituye nuestro mundo no nos lleva a anomalías o a la anarquía, sino a la premonición de un Derecho que es más restrictivo y mucho más aterrador que ningún otro que el mundo moderno haya nunca conocido, difícil de poder describir con palabras. Lo que esta premonición revela es la arcaica "Ley de la necesidad", la que únicamente puede entenderse a través de los infortunios de aquellos que, sin darse cuenta, la transgreden. Así, Kafka nos relaciona con un viejo mundo contaminado de impurezas y decadencia, que aparece como una fuerza maligna de la naturaleza. Este mundo, indiferente a la bondad o a la maldad de las intenciones de los sujetos, es el de una "justicia inmanente", en el que sus proclamaciones son tan inexplicables como implacables, del que resulta, como se describe en la oración inicial de El proceso, que un buen día te encuentras arrestado sin saber por qué.

Entre una justicia ideal, en la que sin duda se inspira, y esta justicia inmanente, por la que nunca deja de sentirse aterrado, Kafka construye una inmensa y enigmática obra que nunca deja de fascinarnos. Sólo la Oresteia de Esquilo se acerca un poco al abismo que subyace al trabajo sobre la justicia.

Conforme nos vamos acercando al final de este paseo por el mundo de las letras, me doy cuenta de que ni una vida entera sería suficiente para poder circunscribir todo 
este tema. Al menos pudimos haber considerado también a Fausto, que vendió su alma al diablo y en vano trató de romper aquel terrible pacto. O Antonio, el glorioso "Mercader de Venecia", quien por poco no escapa de ese nefasto acuerdo y tiene que pagar una onza de su propia carne. Tuvimos que haber seguido las revueltas y los juicios de Michaël KolHASs, la indomable rebeldía para exigir justicia de Heinrich Von Kleist. Tuvimos que haber recordado La guerre de Troie n'aura pas lieu de Jean Giraudoux y las lamentables contorsiones del abogado de Hector, Bursis, quien después de claudicar tuvo éxito en hacer del Derecho «la escuela más poderosa de la imaginación».

Pero para aprehender el milagroso encuentro entre el Derecho y la literatura no es necesario citar a los clásicos. Este milagro también se puede encontrar en trabajos más modestos, como los cuentos. Con uno de ellos quisiera concluir. Se titula Le douzième chameau: histoire arabe ${ }^{10}$. Un padre, al morir, deja once camellos a sus tres hijos para que fueran divididos de la siguiente manera: la mitad para el mayor, un cuarto para el segundo hijo y un sexto para el tercero de ellos. Inmediatamente esta división aparenta ser imposible. Enojados y al borde de la violencia, los tres hermanos se apresuraron a que un juez decidiera por ellos. Este cadi, que tuvo que haber sido una persona muy brillante, así como un buen matemático, al ver el problema del que se trataba, decide agregar uno de sus camellos a la división, con la condición de que le sea devuelto tan pronto ésta sea resuelta. Hecha la división con los doce camellos, el mayor de los hermanos se retira con seis, el segundo recibe tres y el más joven recibe dos. Cada uno de ellos queda satisfecho y le es devuelto su camello al juez.

Si matemáticamente este problema puede ser sencillamente explicado, filosóficamente la explicación no es tan sencilla. ¿En qué consiste exactamente el duodécimo camello? Por supuesto, se trata de una ficción; uno actúa "como si" en realidad hubiera doce camellos para ser divididos en lugar de once. Pero ¿qué es lo que este simbolismo oculta? ¿Qué expresa este juez al "añadir algo de su propiedad"? ¿Qué hay detrás de este complemento que reanima una negociación baldada? Se podría decir que se trata de la mediación judicial: del arsenal de procedimientos, del artificio conceptual, del montaje de reglas y principios, de todo el andamiaje convencional para resolver litigios. Sin duda. Pero chay algo más? Debemos tener mucho cuidado de no cerrar la pregunta con una respuesta apresurada; debemos permitirle al enigma literario que haga que esta pregunta vibre hasta donde sea posible.

En conclusión, quisiera de nuevo subrayar que debemos hacerle justicia a la dimensión literaria que se merecen los trabajos en cuestión, mucho más allá de lo que se ha hecho en esta tentativa de análisis. Los textos nunca deben ser reducidos al estatus secundario de embellecimiento de una tesis o a la excusa humanística de la demostración. Así, tan pronto encaminemos la lectura de un texto tendremos que re-abrir asiduamente el juego de la interpretación.

Por ejemplo, al margen de las tragedias escritas por Kafka, deberíamos haber recordado algunas de sus grotescas páginas que son las que acentúan la belleza enigmática de su obra. Siguiendo la misma línea de interpretación sugerida por Lacan, deberíamos haber liberado a Antígona de la hagiografía en la que se encuentra encerrada — sus

10 2004: «Le douzième chameau, ou l'économie de la justice», en Liber amicorum Guy Horsmans (en honor a Guy Horsmans), Brussels: Bruylant, pp. 843-867. 
mortales e incestuosas inclinaciones por su amor de hermana-. Deberíamos haber leído entre las edificantes líneas de DEFOE para discernir los indicios de la auto-irrisión de Robinson, que son en realidad lo que le salvan de reducirse a una apología del trabajo ascético.

El filósofo del Derecho que se aventura en las costas de la literatura es una especie de Colón, que al asentar pie en el nuevo mundo ignora la exacta naturaleza de su descubrimiento. ¿Es acaso una isla o un continente? Serán muchos más los descubrimientos que lo estarán esperando y, con toda seguridad, se verá obligado a modificar los mapas que presuntamente ya había delineado. Así, podemos partir hacia la búsqueda de los fundamentos del Derecho, pero si encontramos algunos de ellos por el lado del Derecho, del juez y de la conciencia, no habremos fallado en encontrar los abismos que se abren bajo nuestros pies, reabriendo las preguntas sobre estos fundamentos por lo que respecta al crimen, las ficciones, a la violencia y a una muy arcaica Ley de la necesidad. Lo que aquí se sugiere es una historia muy distinta (la que describe una parte escondida del Derecho y de las instituciones), una dimensión sin duda reprimida, pero siempre lista para romper la delgada capa que cubre a la civilización ${ }^{11}$.

Platón, el filósofo de la ciudad ideal, desterró a poetas y escritores de tragedias, peligrosos rivales del arte de la simulación. Mi deseo es que en la ciudad real éstos sean escuchados con atención por princesas y legisladores. Al menos, de vez en cuando.

(Trad. de René González de la Vega)

${ }^{11}$ Véase mi Sade et la loi, Paris: Odile Jacobe, 2005.

\section{$\triangle \quad$ DOXA 29 (2006)}

